\title{
Corrigendum: Low-Cost Avoidance Behaviors are Resistant to Fear Extinction in Humans
}

\section{OPEN ACCESS}

Edited and reviewed by:

Denise Manahan-Vaughan,

Ruhr University Bochum, Germany

${ }^{*}$ Correspondence: Bram Vervliet

bram.vervliet@ppw.kuleuven.be

Specialty section: This article was submitted to

Learning and Memory

a section of the journal

Frontiers in Behavioral Neuroscience

Received: 21 January 2021

Accepted: 26 January 2021

Published: 25 February 2021

Citation:

Vervliet B and Indekeu E (2021) Corrigendum: Low-Cost Avoidance

Behaviors are Resistant to Fear Extinction in Humans. Front. Behav. Neurosci. 15:656847. doi: 10.3389/fnbeh.2021.656847
Bram Vervliet ${ }^{1,2 *}$ and Ellen Indekeu ${ }^{3}$

1 Department of Psychiatry, Massachusetts General Hospital and Harvard Medical School, Boston, MA, United States,

${ }^{2}$ Center for Excellence on Generalization in Health and Psychopathology, University of Leuven-KU Leuven, Leuven,

Belgium, ${ }^{3}$ Department of Psychology, University of Leuven-KU Leuven, Leuven, Belgium

Keywords: fear, extinction, avoidance, response prevention, exposure

\section{A Corrigendum on}

Low-Cost Avoidance Behaviors Are Resistant to Fear Extinction in Humans

by Vervliet, B., and Indekeu, E. (2015). Front. Behav. Neurosci. 9:351. doi: 10.3389/fnbeh.2015.00351

In the original article, there was a mistake in Figure 3 as published. Panel C of Figure 3 presented the skin conductance results of Experiment 1, instead of Experiment 2. The corrected Figure 3 appears below.

The authors apologize for this error and state that this does not change the scientific conclusions of the article in any way. The original article has been updated.

Copyright $(\odot 2021$ Vervliet and Indekeu. This is an open-access article distributed under the terms of the Creative Commons Attribution License (CC BY). The use, distribution or reproduction in other forums is permitted, provided the original author $(s)$ and the copyright owner(s) are credited and that the original publication in this journal is cited, in accordance with accepted academic practice. No use, distribution or reproduction is permitted which does not comply with these terms. 


\section{EXPERIMENT 2}

A

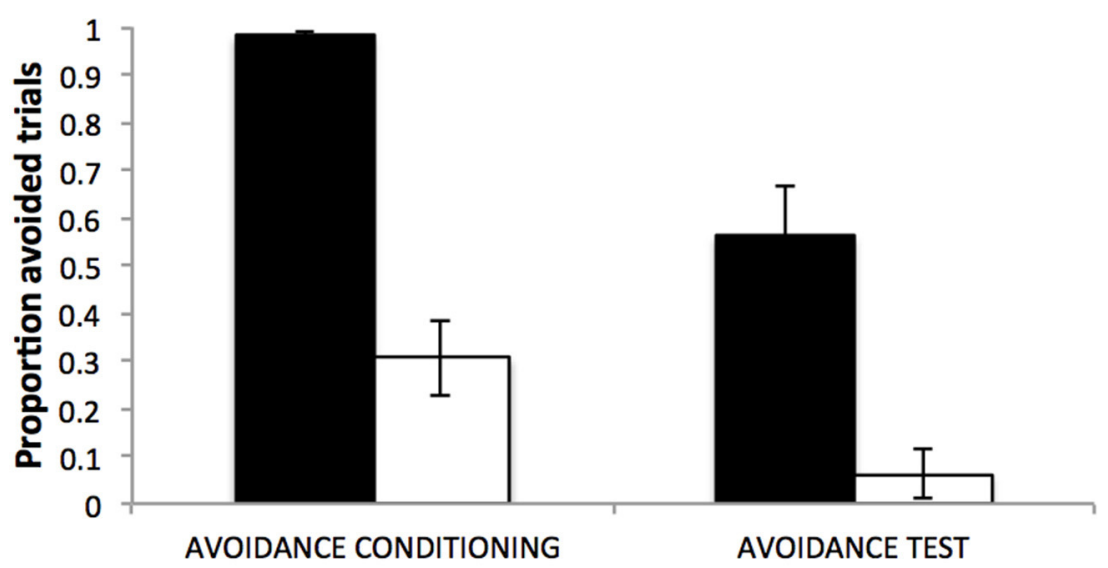

B
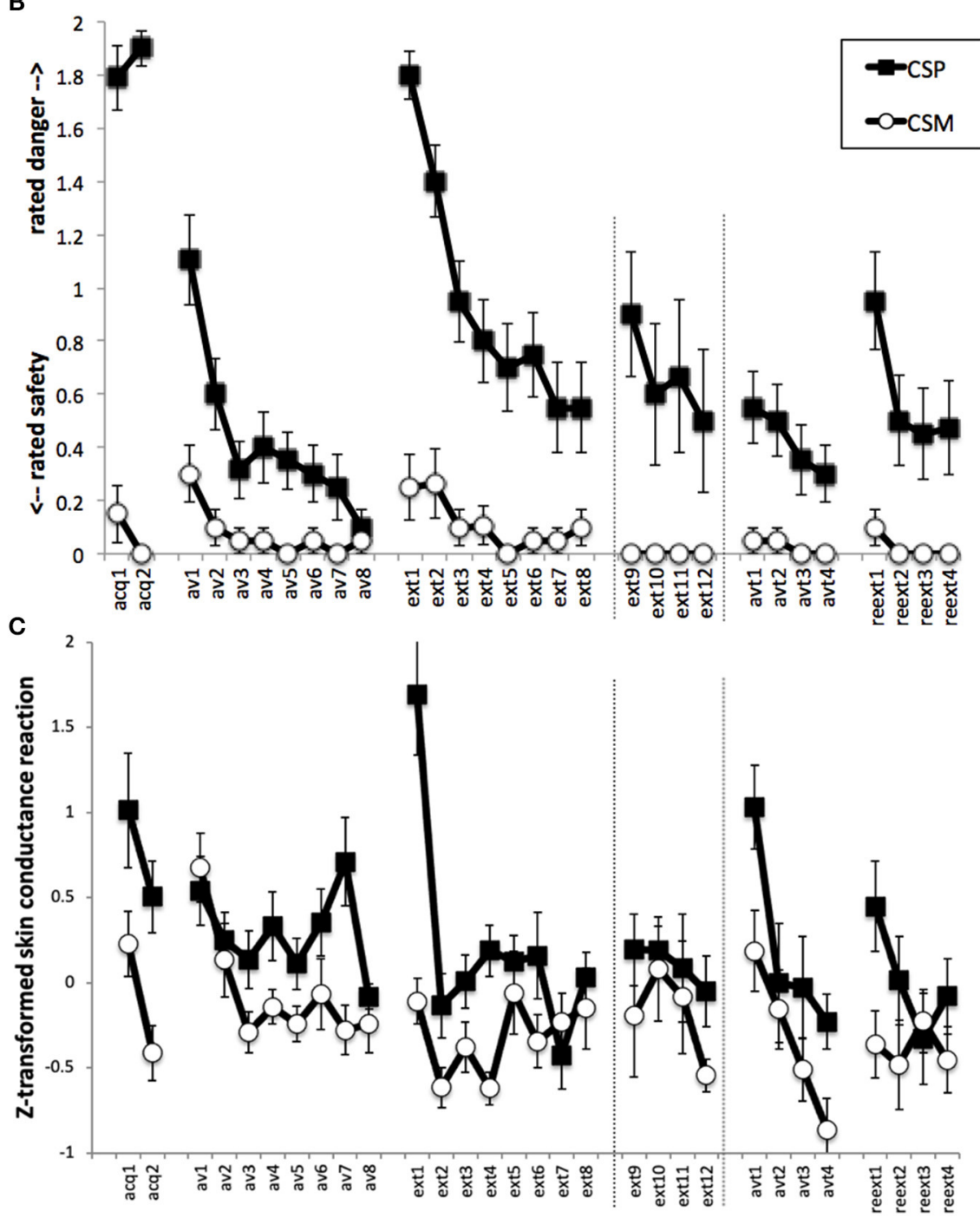

FIGURE 3 | Results from Experiment 2. (A): Proportions of CSP and CSM trials during which the avoidance button was clicked, for avoidance conditioning and avoidance test phase separately. (B): Mean shock-expectancy ratings during CSP and CSM ( $0=$ "safe," $1=$ "uncertain," $2=$ "danger"), for all trials of Pavlovian conditioning (acq1-2), avoidance conditioning (av1-8), response prevention and extinction (ext1-8) with extension for Group ExtLong between the dashed lines (ext9-12), avoidance test (avt1-4), and reextinction (reext1-4). (C): Z-transformed skin conductance reactions during CSP and CSM during all trials (cf. B). Error bars represent standard errors of the means. 